\title{
КЛИНИЧЕСКАЯ ОЦЕНКА РАЗРАБОТАННОЙ ТЕХНОЛОГИИ КОМБИНИРОВАННОГО ЛАЗЕРНОГО ЛЕЧЕНИЯ ПРИ НАЧАЛЬНЫХ СТАДИЯХ ИДИОПАТИЧЕСКОЙ ЭПИРЕТИНАЛЬНОЙ МЕМБРАНЫ
}

Х. П. Тахчиди ${ }^{1,2}$, Г. Ф. Качалина ${ }^{2}$, Т. А. Касмынина², Е. П. Тебина ${ }^{3}$

${ }_{1}$ Российский национальный исследовательский медицинский университет имени Н. И. Пирогова, Москва, Россия

${ }^{2}$ Научно-исследовательский центр офтальмологии, Российский национальный исследовательский медицинский университет имени Н. И. Пирогова, Москва, Россия

${ }^{3}$ Педиатрический факультет, Российский национальный исследовательский медицинский университет имени Н. И. Пирогова, Москва, Россия

\begin{abstract}
Одной из актуальных проблем витреоретинальной патологии является процесс формирования эпиретинальной мембраны (ЭРМ) на ретинальной поверхности макулярной зоны. До настоящего времени не существует эффективных методов, оказывающих антипролиферативное и антиконстрикторное действие на фиброзный процесс на начальных этапах его развития. Целью исследования являлась оценка эффективности и безопасности технологии комбинированного лазерного лечения пациентов с начальными стадиями (0-1 стадия) идиопатической ЭРМ. В клиническое исследование были включены 92 пациента (64,7 \pm 9,6 лет). Основную группу составили 32 пациента (32 глаза), которым было проведено лазерное лечение по комбинированной технологии. Группу сравнения составили 30 пациентов (30 глаз), лечение которых осуществлялось с применением лазерной коагуляции по типу «решетки». В контрольную группу были включены 30 пациентов (30 глаз), у которых было установлено динамическое наблюдение за естественным течением пролиферативного процесса без лазерного и консервативного лечения. По результатам офтальмологического обследования проводилась оценка некоррегированной остроты зрения, максимально коррегированной остроты зрения, центральной толщины сетчатки и центральной светочувствительности сетчатки. Разработанная технология комбинированного лазерного лечения показала высокую эффективность, заключающуюся в сохранении/увеличении зрительно-функциональных показателей и стабилизации/улучшении морфофрункциональных показателей сетчатки в течение всего периода наблюдения. Безопасность и эффективность разработанной лазерной технологии в отношении морфофункциональных структур сенсорной сетчатки отражалась в увеличении показателей светочувствительности сетчатки в различные сроки наблюдения.
\end{abstract}

Ключевые слова: идиопатическая эпиретинальная мембрана, субпороговое микроимпульсное лазерное воздействие, комбинированная лазерная технология, оптическая когерентная томография

Информация о вкладе авторов: Х. П. Тахчиди, Г. Ф. Качалина - концепция и дизайн исследования; Е. П. Тебина - сбор и обработка материала; Т. А. Касмынина - лазерное лечение пациента; Т. А. Касмынина, Е. П. Тебина - написание текста; Х. П. Тахчиди - редактирование.

Соблюдение этических стандартов: исследование одобрено этическим комитетом РНИМУ имени Н. И. Пирогова (протокол № 160 от 19 декабря 2016 г.).

$\bowtie$ Для корреспонденции: Екатерина Павловна Тебина

Волоколамское шоссе, д. 30, корп. 2, г. Москва, 123182; ekaterinatebina@mail.ru

Статья получена: 18.03.2019 Статья принята к печати: 02.04.2019 Опубликована онлайн: 30.04.2019

DOI: $10.24075 /$ vrgmu.2019.033

\section{COMBINED LASER TREATMENT OF EARLY IDIOPATHIC EPIRETINAL MEMBRANE: CLINICAL EVALUATION OF THE DEVELOPED TECHNIQUE}

Takhchidi KP',2, Kachalina $\mathrm{GF}^{2}$, Kasminina $\mathrm{TA}^{2}$, Tebina $\mathrm{EP}^{3} \otimes$

${ }^{1}$ Pirogov Russian National Research Medical University, Moscow, Russia

${ }^{2}$ Research Center for Ophthalmology, Pirogov Russian National Research Medical University, Moscow, Russia

${ }^{3}$ Faculty of Pediatrics, Pirogov Russian National Research Medical University, Moscow, Russia

Process of development of epiretinal membrane (ERM) on the retinal surface of macular area is one of the important problems associated with vitreoretinal pathologies. Up to the present day, there has not been developed an effective method to arrest fibrosis at the early stages of its development. This study aimed to evaluate efficacy and safety of the new combined laser technique designed to treat early idiopathic ERM (stages 0-1). Ninety-two patients aged $64.7 \pm 9.6$ years (mean) participated in the clinical research. They were divided into three groups: treatment group $(n=32)$, patients whose ERM was treated following the new combined laser technique; comparison group $(n=30)$, patients who underwent grid laser coagulation; control group $(n=30)$, no treatment, observation of the natural course. Based on the results of examination of the patients, we assessed uncorrected visual acuity, best corrected visual acuity, central retinal thickness, central retinal sensitivity. Assessed against the results registered in comparison and control groups, the developed combined laser treatment technique applied in the treatment group proved to be highly effective in maintaining/improving visual functional indicators and stabilizing/improving morphofunctional indicators throughout the entire period of observation. As pertains to the morphological and functional structures of sensory retina, the technique enabled retinal sensitivity improvement at different stages of observation, which reflects its safety and efficacy.

Keywords: idiopathic epiretinal membrane, subthreshold micropulse laser exposure, combined laser technology, optical coherent tomography

Author contribution: Takhchidi KP and Kachalina GF conceived and designed the study; Tebina EP collected and analyzed the data; Kasminina TA performed laser therapy; Kasminina TA, and Tebina EP wrote the manuscript; Takhchidi KP revised the manuscript.

Compliance with ethical standards: the study was approved by Russian National Research Medical University (Protocol № 160 of December 19, 2016).

$\triangle$ Correspondence should be addressed: Ekaterina P. Tebina

Volokolamskoe shosse 30, bld. 2, 123182; ekaterinatebina@mail.ru

Received: 18.03.2019 Accepted: 02.04.2019 Published online: 30.04.2019

DOI: 10.24075/brsmu.2019.033

За последние годы изучения фиброзных процессов в офтальмологии проведено немало научных исследований, посвященных проблеме формирования соединительной ткани в полости глазного яблока [1-4]. Тем не менее особое место среди витреоретинальной патологии занимает фиброзное поражение макулярной зоны, приводящее к 
значительному снижению и зачастую к необратимой потере зрительной функции у людей трудоспособного возраста.

Несмотря на прогресс в изучении этиопатогенетических механизмов формирования эпиретинальной мембраны (ЭРМ), аспекты их развития до сих пор остаются неизвестными [5]. К основным этиологическим факторам данной патологии относят: нарушение биомеханических процессов на границе витреоретинального интерфейса, а именно - заднюю отслойку стекловидного тела (ЗОСТ), наличие «микропор» во внутренней пограничной мембране (ВПМ) и патологические изменения в микроциркуляторном русле макулярной зоны [6-8]. Вне зависимости от патогенетического механизма развития ЭРМ ключевую роль в ее формировании и прогрессировании отводят миграции и пролиферации различных типов клеток, таких как глиальные клетки (ретинальные клетки Мюллера, астроциты и микроглия), гиалоциты, макрофаги, ретинальный пигментный эпителий (РПЭ) и фибробласты на ретинальной поверхности [9, 10]. Под воздействием цитокинов и факторов роста представленный ряд клеток подвергается трансдифференцировке в фенотип, схожий с миофибробластами, которые при асептическом воспалении подвергаются апоптозу [11, 12]. В случае фиброзных заболеваний миофибробласты активизируются и при длительной персистенции приводят к чрезмерному отложению коллагена с последующим его ремоделированием [13]. Выделяют три основные стадии развития ЭРМ: 0 - «целлофановой макулопатии», 1 - «гофрированной целлофановой макулопатии» и 2 - «макулярного сморщивания» [14]. В зависимости от стадии развития ЭРМ клинические проявления заболевания могут варьироваться от полного отсутствия симптомов до значительного ухудшения зрительной функции [15]. На сегодняшний день не существует безопасных и эффективных методов, способных затормозить клеточную пролиферацию и замедлить прогрессирование фиброзного процесса на его ранних стадиях.

ЭРМ на поздних стадиях его развития успешно лечится при помощи витреоретинальной хирургии. Несмотря на эффективность оперативного вмешательства, в ходе гистологических исследований было установлено, что в процессе пиллинга ВПМ происходит повреждение клеток Мюллера с нарушением архитектоники и прочности сетчатки [16, 17]. В результате нарушения биомеханических свойств сетчатки восстановление зрительной функции в послеоперационном периоде происходит не полностью, а лишь в 5-25\% случаев [18]. K тому же данный вид лечения применим при наличии выраженных клинических симптомов, связанных с изменением и/или снижением зрительной функции. До этого момента основной тактикой ведения пациентов с ЭРМ является динамическое наблюдение [19].

Таким образом, актуальным остается вопрос разработки нового эффективного и безопасного метода лечения ЭРМ на начальных стадиях. С целью стабилизации и/или улучшения показателей зрительной функции у пациентов с ЭРМ на базе Научно-исследовательского центра офртальмологии РНИМУ имени Н. И. Пирогова была разработана комбинированная лазерная технология, сочетающая в себе две разные по механизму действия методики: лазерную коагуляцию по типу «решетки» и субпороговое микроимпульсное воздействие лазерного излучения с длиной волны 577 нм (патент РФ № 2634684 от 2 ноября 2017 г.) [20]. В статье представлены результаты клинического исследования эффективности и безопасности разработанной методики лечения пациентов с начальными стадиями (0-1) идиопатической эпиретинальной мембраны.

\section{ПАЦИЕНТЫ И МЕТОДЫ}

В исследование включено 92 пациента (64,7 \pm 9,6 лет). Критерии включения: пациенты любого пола; наличие начальной стадии идиопатической ЭРМ (0-1 стадия) с сопутствующей патологией хрусталика: артифакия или начальная катаракта.

Все пациенты методом простой рандомизации были разделены на три группы, в зависимости от предполагаемой тактики ведения. Основную группу составили 32 пациента (32 глаза), которым было проведено лазерное лечение по комбинированной технологии. Группу сравнения составили 30 пациентов (30 глаз), лечение которых осуществляли с применением лазерной коагуляции по типу «решетки». В контрольную группу были включены 30 пациентов (30 глаз), у которых было установлено динамическое наблюдение за естественным течением пролиферативного процесса без лазерного и консервативного лечения.

Технология комбинированного лазерного лечения включает в себя сочетание лазерной коагуляции по типу «решетки» и субпорогового микроимпульсного лазерного воздействия [20]. Проведение лазерного лечения

Таблица 1. Протокол разработанной комбинированной лазерной технологии для лечения пациентов с ЭРМ

\begin{tabular}{|c|c|c|}
\hline \multirow{13}{*}{ Энергетические параметры } & \multicolumn{2}{|c|}{ Лазерная коагуляция по типу «решетки» } \\
\hline & Длина волны (нм) & 577 \\
\hline & Диаметр пятна (мкм) & 100 \\
\hline & Мощность излучения (мВт) & 50 \\
\hline & Длительность микроимпульса (мкс) & 50 \\
\hline & Количество аппликатов & $60-90$ \\
\hline & \multicolumn{2}{|c|}{ Субпороговое микроимпульсное лазерное воздействие } \\
\hline & Длина волны (нм) & 577 \\
\hline & Диаметр пятна (мкм) & 100 \\
\hline & Мощность излучения (мВт) & 50 \\
\hline & Длительность микроимпульса (мкс) & 50 \\
\hline & Длительность пакета микроимпульсов (мс) & 30 \\
\hline & Скважность (\%) & 4,7 \\
\hline
\end{tabular}


осуществляли на установке «IRIDEX IQ 577» (IRIDEX Corporation, Mountain View; CШA), которая позволяет работать как в непрерывном, так и в микроимпульсном режимах.

Первым этапом лечения основной группе проводили лазерную коагуляцию сетчатки по типу «решетки» по всей поверхности ЭРМ, исключая аваскулярную зону, со следующими энергетическими параметрами: длина волны 577 нм, мощность 50 мВт, длительность импульса 0,05 с, диаметр пятна 100 мкм, расстояние между лазеркоагулятами 150 мкм. Через 2 недели проводили второй этап комбинированного лазерного лечения: субпороговое микроимпульсное лазерное воздействие длиной волны 577 нм, длительностью пакета 30 мс, длительностью микроимпульса 50 мкс, скважностью 4,7\%, диаметром пятна 100 мкм, мощностью 50 мВт (табл. 1). В основой группе было проведено три сеанса суборогового микроимпульсного лазерного воздействия с интервалом 1 месяц, в связи с отсутствием статистически значимых изменений после 4-го сеанса.

Bce пациенты были обследованы с помощью стандартных офтальмологических и специальных методов исследования: мультиспектрального исследования с использованием различных фрильтров (Blue, Green, Infrared Reflectance, MultiColor), спектральной оптической когерентной томографии (COKT) с помощью «Spectralis OCT» (Heidelberg Engineering Inc; Германия) и микропериметрии MAIA (CenterVue; Италия).

Обследования всех клинических групп проводили до начала исследования, а также в сроки - 3 месяца, 6 месяцев, 1 год, 2 года, 3 года, 4 года и 5 лет. Дополнительно в первых двух группах обследования проводили после каждого этапа лазерного воздействия.

Таблица 2. Динамика клинико-функциональных показателей пациентов с ЭРМ в течение 5 лет

\begin{tabular}{|c|c|c|c|c|}
\hline Период наблюдения & Основная группа & Группа сравнения & Контрольная группа & ANOVA, $p$ \\
\hline \multicolumn{5}{|c|}{ Средняя некоррегированная острота зрения } \\
\hline До лечения & $0,45 \pm 0,31$ & $0,44 \pm 0,26$ & $0,64 \pm 0,23$ & 0,01 \\
\hline 3 месяца & $0,57 \pm 0,3^{*}$ & $0,47 \pm 0,27^{*}$ & $0,63 \pm 0,23^{\star}$ & 0,08 \\
\hline 6 месяцев & $0,59 \pm 0,31^{*}$ & $0,43 \pm 0,27^{\star}$ & $0,6 \pm 0,24^{*}$ & 0,13 \\
\hline 1 год & $0,61 \pm 0,31^{*}$ & $0,42 \pm 0,27^{*}$ & $0,56 \pm 0,26^{\star}$ & 0,04 \\
\hline 2 год & $0,61 \pm 0,3^{*}$ & $0,42 \pm 0,27^{*}$ & $0,53 \pm 0,25^{\star}$ & 0,03 \\
\hline 3 год & $0,6 \pm 0,3^{\star}$ & $0,42 \pm 0,27^{*}$ & $0,48 \pm 0,26^{*}$ & 0,03 \\
\hline 4 год & $0,61 \pm 0,2^{*}$ & $0,42 \pm 0.27^{\star}$ & $0,45 \pm 0,27^{\star}$ & 0,01 \\
\hline 5 год & $0,61 \pm 0,29^{*}$ & $0,41 \pm 0,27^{*}$ & $0,43 \pm 0,28^{\star}$ & 0,01 \\
\hline \multicolumn{5}{|c|}{ Средняя максимально коррегированная острота зрения } \\
\hline До лечения & $0,9 \pm 0,13$ & $0,86 \pm 0,15$ & $0,87 \pm 0,14$ & 0,53 \\
\hline 3 месяца & $0,95 \pm 0,1^{*}$ & $0,85 \pm 0,16$ & $0,85 \pm 0,14^{*}$ & 0,007 \\
\hline 6 месяцев & $0,95 \pm 0,1^{*}$ & $0,85 \pm 0,16$ & $0,85 \pm 0,14^{*}$ & 0,007 \\
\hline 1 год & $0,95 \pm 0,1^{*}$ & $0,83 \pm 0,17^{*}$ & $0,83 \pm 0,17^{\star}$ & 0,001 \\
\hline 2 год & $0,95 \pm 0,1^{*}$ & $0,81 \pm 0,18^{*}$ & $0,8 \pm 0,17^{*}$ & 0,000 \\
\hline 3 год & $0,94 \pm 0,1^{*}$ & $0,78 \pm 0,19^{*}$ & $0,75 \pm 0,2^{*}$ & 0,000 \\
\hline 4 год & $0,94 \pm 0,1^{*}$ & $0,76 \pm 0,19^{*}$ & $0,7 \pm 0,23^{*}$ & 0,000 \\
\hline 5 год & $0,94 \pm 0,1^{*}$ & $0,73 \pm 0,21^{*}$ & $0,68 \pm 0,24^{*}$ & 0,000 \\
\hline \multicolumn{5}{|c|}{ Средняя светочувствительность сетчатки в центральной зоне } \\
\hline До лечения & $26,3 \pm 1,65$ & $26,3 \pm 1,57$ & $27,1 \pm 1,52$ & 0,13 \\
\hline 3 месяца & $27,0 \pm 1,5^{\star}$ & $26,6 \pm 1,68$ & $26,8 \pm 1,56^{*}$ & 0,61 \\
\hline 6 месяцев & $27,1 \pm 1,5^{\star}$ & $26,5 \pm 1,73$ & $26,6 \pm 1,62^{*}$ & 0,51 \\
\hline 1 год & $27,1 \pm 1,5^{*}$ & $26,2 \pm 1,5$ & $26,2 \pm 1,68^{\star}$ & 0,06 \\
\hline 2 год & $27,1 \pm 1,5^{*}$ & $25,9 \pm 1,52^{*}$ & $26 \pm 1,68^{*}$ & 0,01 \\
\hline 3 год & $27,1 \pm 1,5^{*}$ & $25,7 \pm 1,69^{*}$ & $25,7 \pm 1,78^{*}$ & 0,002 \\
\hline 4 год & $27,1 \pm 1,5^{*}$ & $25,6 \pm 1,71^{*}$ & $25,5 \pm 1,92^{*}$ & 0,000 \\
\hline 5 год & $27,1 \pm 1,5^{\star}$ & $25,5 \pm 1,79^{\star}$ & $25,4 \pm 1,88^{\star}$ & 0,000 \\
\hline \multicolumn{5}{|c|}{ Средняя толщина сетчатки в центральной зоне } \\
\hline До лечения & $282,8 \pm 27,1$ & $292,4 \pm 62,2$ & $301,4 \pm 44,8$ & 0,37 \\
\hline 3 месяциа & $277,6 \pm 42,9$ & $291,7 \pm 63,6$ & $308,8 \pm 45,1^{*}$ & 0,06 \\
\hline 6 месяцев & $277,5 \pm 42,5$ & $293,6 \pm 64,6$ & $316,6 \pm 43,2^{*}$ & 0,01 \\
\hline 1 год & $277,7 \pm 44,4$ & $300 \pm 65,6^{*}$ & $323,6 \pm 43,6^{*}$ & 0,003 \\
\hline 2 год & $277,1 \pm 41,5$ & $303,9 \pm 65,1^{*}$ & $331,5 \pm 49^{*}$ & 0,000 \\
\hline 3 год & $274,9 \pm 41,2^{*}$ & $304 \pm 63,9^{*}$ & $338,1 \pm 48,1^{\star}$ & 0,000 \\
\hline 4 год & $274,9 \pm 41,8^{*}$ & $306,5 \pm 63,4^{*}$ & $345,9 \pm 48,1^{*}$ & 0,000 \\
\hline 5 год & $275,1 \pm 42,2^{*}$ & $309,7 \pm 63,2^{*}$ & $349,7 \pm 49,1^{*}$ & 0,000 \\
\hline
\end{tabular}

Примечание: * - данные статистически значимо отличаются от исходных значений, $t$-критерий Стьюдента для повторных измерений (p < 0,05), ANOVA $(p<0,05)$. 
Клиническую оценку безопасности лазерного лечения выполняли на основе данных светочувствительности сетчатки в центральной зоне.

Основными исследуемыми показателями являлись некоррегированная острота зрения (НКОЗ), максимально коррегированная острота зрения (МKO3), толщина сетчатки в центральной зоне (ЦТС) и центральная светочувствительность сетчатки. Показатели подчинялись нормальному распределению и оценивались с помощью методов параметрической статистики. Для оценки различий между полученными результатами лечения в различные сроки наблюдения относительно исходных значений в каждой группе применяли $t$-критерий Стьюдента для повторных измерений. Для оценки достоверности различий при сравнении результатов более чем двух независимых групп использовали однофакторный дисперсионный анализ (ANOVA). Статистически значимыми считали результаты при $p<0,05$.

\section{РЕЗУЛЬТАТЫ}

В основной группе пациентов (32 глаза) НКОЗ оказалась равной 0,45 \pm 0,31, МКОЗ составила 0,9 \pm 0,13. По данным компьютерной микропериметрии, средняя светочувствительность (С4) сетчатки составила 26,3 \pm 1,65 дБ. По данным ОКТ, средняя толщина сетчатки в центральной зоне достигала значений $282,8 \pm 27,1$ мKM.

В группе сравнения (30 глаз) предоперационные показатели средней НКОЗ составили 0,44 \pm 0,26, средняя МКОЗ - 0,86 \pm 0,15. Средняя СЧ сетчатки была равна $26,3 \pm 1,57$. По данным COKT, средняя толщина сетчатки в центральной зоне составила 292,4 \pm 62,2 мкм.

По результатам обследования группы контроля (30 глаз), средняя НКO3 - 0,64 $\pm 0,23, \mathrm{MKO}-0,87 \pm 0,14$. По результатам компьютерной микропериметрии, средняя С4 сетчатки составила 27,1 \pm 1,52 дБ. По данным СОКТ,

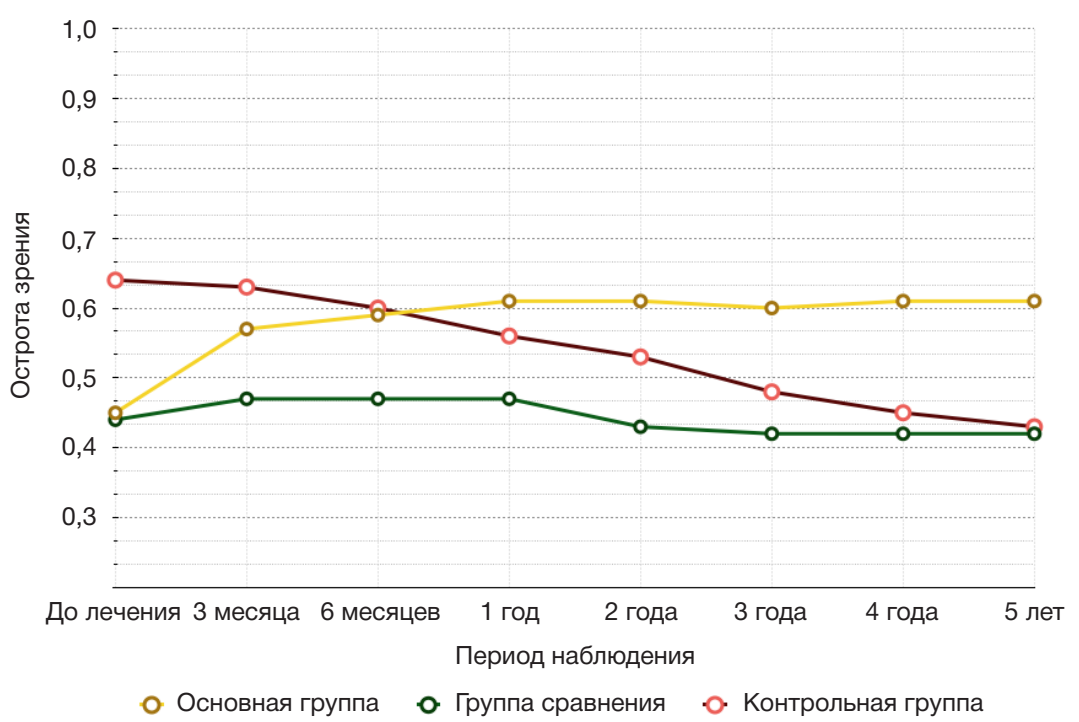

Рис. 1. Динамика средней НКОЗ пациентов исследуемых групп. В основной группе пациентов (желтая линия) показатели средней НКОЗ достигли статистически достоверного увеличения в сроки с 3-го по 12-й месяцы наблюдения с сохранением максимальных значений до окончания срока наблюдения. В группе сравнения (зеленая линия) значения средней НКОЗ достигли статистически значимого увеличения в сроки до З-х месяцев с дальнейшим снижением показателей. В группе контроля (красная линия) показатели средней НКОЗ имели достоверное снижение на всех сроках наблюдения

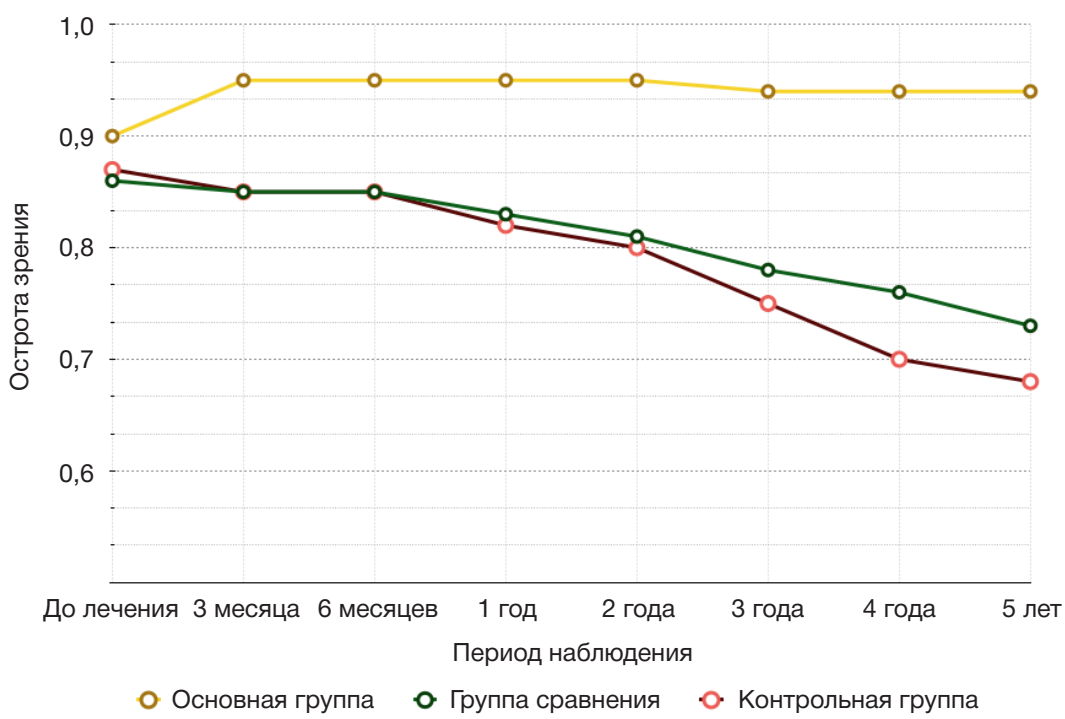

Рис. 2. Динамика средней МКОЗ пациентов исследуемых групп. В основной группе пациентов (желтая линия) показатели средней МКОЗ достигли статистически достоверного увеличения в сроки с 3-го по 12-й месяцы наблюдения и сохраняли максимальные значения до окончания всего срока наблюдения. В группе сравнения (зеленая линия) средняя МКОЗ не имела статистически значимых различий в первые 3 месяца; в дальнейшем ее показатели снижались. В группе контроля (красная линия) показатели средней МКОЗ снижались на всех сроках наблюдения 
средняя толщина сетчатки в центральной зоне достигала значений 301,4 \pm 44,8 мкм.

Анализ клинико-функциональных результатов лечения и динамического наблюдения пациентов с ЭРМ в клинических группах представлен в табл. 2.

В группе контроля показатели средней НКОЗ и средней МКОЗ имели достоверное снижение на всех сроках наблюдения (рис. 1, 2). По данным ОКТ, значения средней ЦТС статистически достоверно увеличивались в период от 3-х месяцев до окончания наблюдения (рис. 3). Средняя СЧ сетчатки в центральной зоне статистически значимо снижалась в сроки от 3-х месяцев до окончания наблюдения (рис. 4). По данным мультиспектрального исследования было отмечено прогрессирование пролиферативного процесса на ретинальной поверхности (рис. 5A, Б).

В группе сравнения значения средней НКОЗ достигли статистически значимого увеличения в сроки до 3-х месяцев, однако с 6 месяцев до окончания наблюдения выявлено статистически значимое снижение показателей (рис. 1). Средняя МКОЗ не имела статистически значимых различий в первые 3 месяца наблюдения, однако после 12 месяцев отмечено постепенное снижение показателя (рис. 2). При анализе средней ЦТС в первые 6 месяцев наблюдения различий от исходных значений не выявлено, однако после 12 месяцев отмечено статистически значимое увеличение ЦТС (рис. 3) и прогрессирование формирования ЭРМ (рис. 6А, Б). По данным компьютерной микропериметрии, показатели средней светочувствительности сетчатки не имели статистически значимых различий в первые 12 месяцев, при этом статистически значимое снижение значений наблюдали в сроки от 2 до 5 лет (рис. 4).

При сравнении результатов лечения и динамического наблюдения между клиническими группами было установлено, что только в основной группе наблюдалось статистически значимое увеличение зрительно-сункциональных показателей

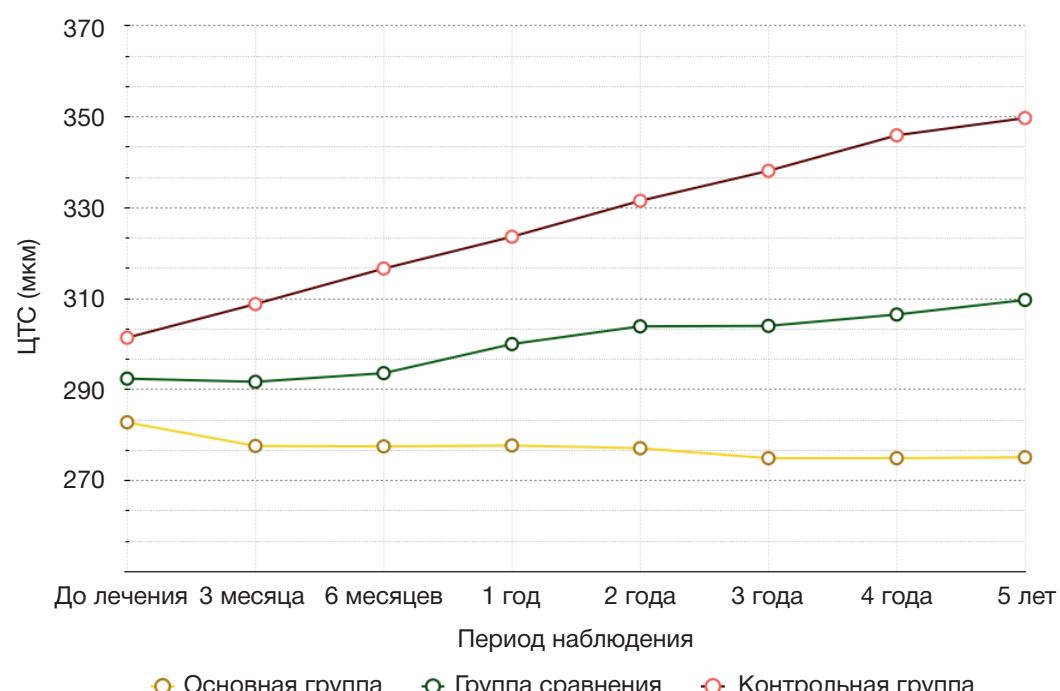

Рис. 3. Динамика средней ЦТС в исследуемых группах пациентов. В основной группе (желтая линия) при анализе средней ЦтС в первые 6 месяцев наблюдения статистически значимых различий с исходными значениями не выявлено, однако в сроки от 12 месяцев наблюдения прослеживается статистически значимое уменьшение показателей. В группе сравнения (зеленая линия) при анализе средней ЦтС в первые 6 месяцев наблюдения статистически значимых различий с исходными значениями не выявлено, однако в сроки от 12 месяцев наблюдения прослеживается статистически значимое увеличение показателей ЦТС. В группе контроля (красная линия) показатели средней ЦТС имели статистически достоверное увеличение в сроки от 3-х месяцев до окончания сроков наблюдения

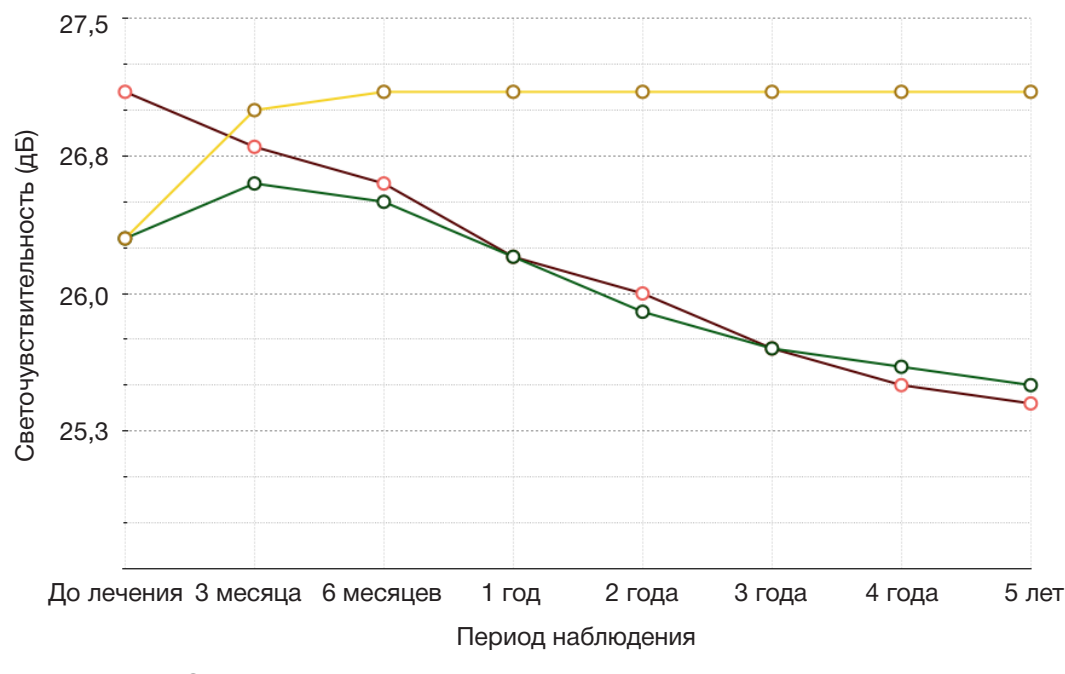

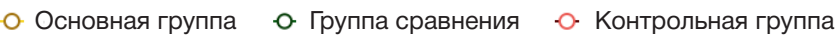

Рис. 4. Динамика средней СЧ сетчатки в исследуемых группах пациентов. В основной группе (желтая линия) средняя СЧ сетчатки имела достоверное статистически значимое увеличение показателей в сроки с 3-го по 12-й месяцы наблюдения, после чего сохраняла максимальные значения до окончания срока наблюдения. В группе сравнения (зеленая линия) показатели средней СЧ сетчатки не имели статистически значимых различий в первые 12 месяцев, однако после двух лет наблюдения показатель снижался. В группе контроля (красная линия) показатели средней СЧ сетчатки достоверно снижались после 3-го месяца наблюдения 

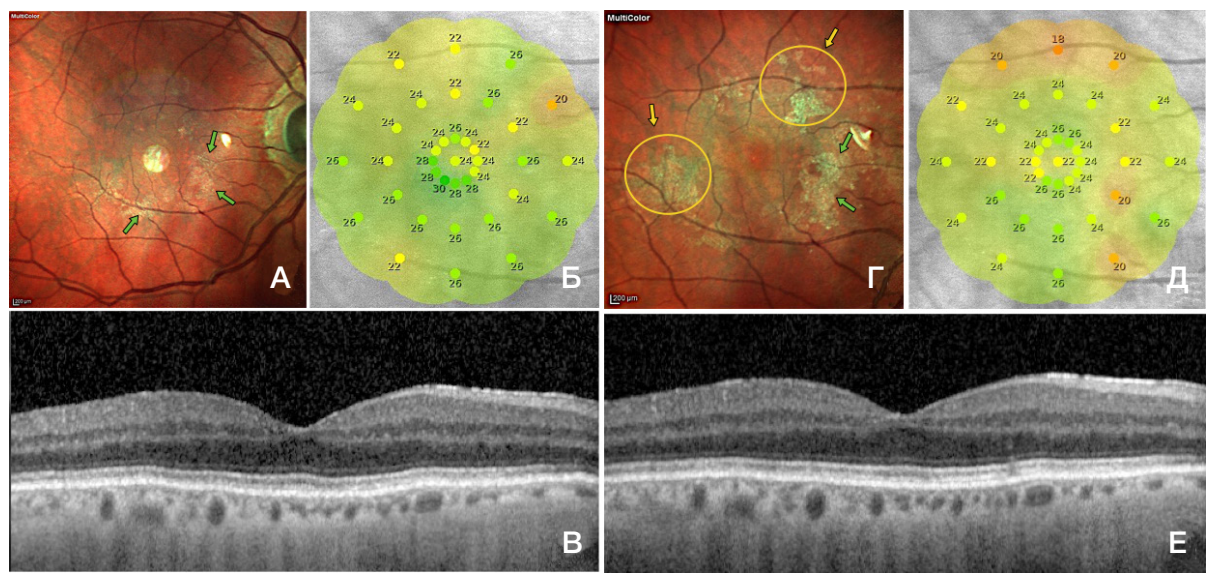

Рис. 5. Контрольная группа. Пациент Э., 58 лет. В начале исследования: по данным мультиспектрального исследования «Мulticolor», в желто-зеленом цвете визуализируются поверхность и границы ЭРМ (А); по данным компьютерной микропериметрии, средняя СЧ сетчатки - 24.9 дБ (Б); по данным COKT, на поверхности ВПМ определяется линия гиперрефлективности, соответствующая ЭРМ, фовеолярный профиль сохранен (В). В срок наблюдения 1 год: по данным мультиспектрального исследования, на поверхности сетчатки отмечается тенденция к прогрессированию пролиферативного процесса и появлению новых очагов ЭРМ (желтая стрелка), а также увеличение площади фиброзного очага в динамике (зеленая стрелка) (Г); средняя СЧ сетчатки 23,5 дБ (Д); по данным СОКТ, на поверхности ВПМ сохраняется наличие ЭРМ, фовеолярный профиль сохранен (Е)
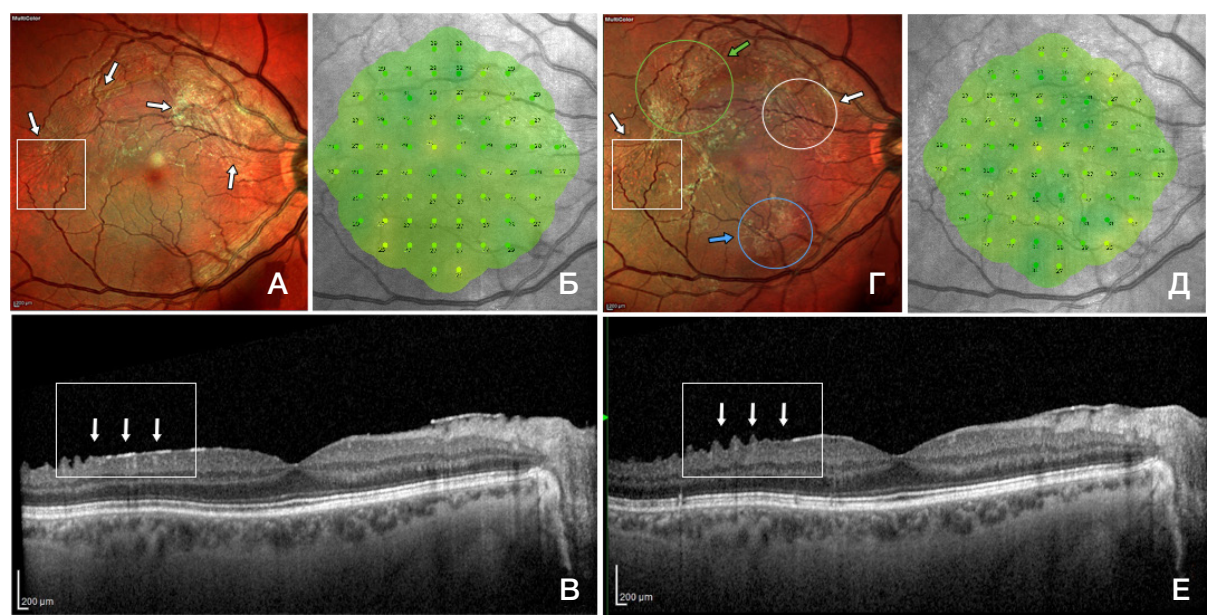

Рис. 6. Группа сравнения. Пациент С., 56 лет. В начале исследования: по данным мультиспектрального исследования «Мulticolor», в желто-зеленом цвете визуализируются поверхность и границы ЭРМ (белая стрелка) (А); по данным компьютерной микропериметрии, средняя СЧ сетчатки - 28,2 дБ (Б); по данным СОКТ, на поверхности ВПМ определяется линия гиперрефлективности, соответствующая ЭРМ (белая стрелка), фовеолярный профиль сохранен, толщина сетчатки в центральной зоне - 239 мкм (В). В двухлетний срок наблюдения по данным мультиспектрального исследования, на фоне лазерных коагулятов определяются участки инволюции ЭРМ (белая стрелка), участки активации ЭРМ (зеленая стрелка) и участки образования новых очагов фиброза (синяя стрелка) (Г); средняя СЧ сетчатки - 27,8 дБ (Д); по данным СОКТ, линия гиперрефлективности (ЭРМ) практически отсутствует (белая стрелка), соответствующий зоне на «Multicolor» (белый квадрат) фовеолярный профиль сохранен, толщина сетчатки в центральной зоне — 237 мкм (Е)

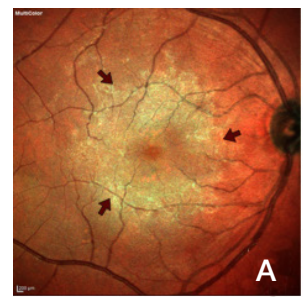

A

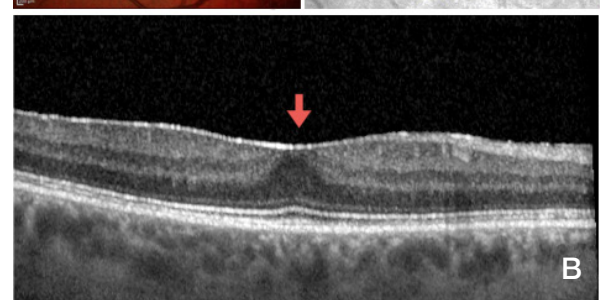

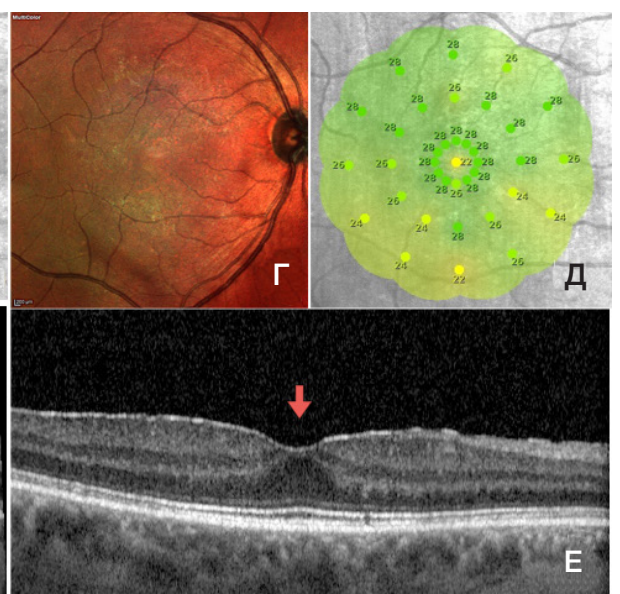

E

Рис. 7. Основная группа. Пациент И., 68 лет. До начала исследования: по данным мультиспектрального исследования («Мulticolor») в желто-зеленом цвете, визуализируются поверхность и границы ЭРМ в начале исследования (красная стрелка) (А); по данным компьютерной микропериметрии, средняя СЧ сетчатки - 26,3 дБ (Б); по данным СОКТ, на поверхности ВПМ определяется линия гиперрефлективности (соответствующая ЭРМ), фовеолярный профиль сглажен (красная стрелка), толщина сетчатки в центральной зоне составила 257 мкм (В). В пятилетний срок наблюдения по данным «Мulticolor», определяется полная инволюция ЭРМ (Г); средняя светочувствительность сетчатки - 26,6 дБ (Д); по данным СОКТ: визуализируется менее «плотная» линия гиперрефлективности (ЭРМ) с формированием фовеолярного профиля (красная стрелка), толщина сетчатки в центральной зоне составила 234 мкм (Е) 
(НКОЗ, МКОЗ и С4) и уменьшение значений средней ЦТС с инволюцией ЭРМ (рис. 7А, Б). Данные показатели оставались максимально стабильными на всех сроках наблюдения, в отличие от группы сравнения, в которой был зарегистрирован кратковременный подъем показателей в сроки до 3 месяцев (НКОЗ, МКОЗ, средняя ЦТС) с последующим их плавным снижением. В группе контроля зрительно-функциональные показатели статистически достоверно снизились на всех сроках наблюдения (рис. 1-4).

При проведении лазерного лечения биомеханического повреждения сенсорной сетчатки не было обнаружено ни в одном случае, что подтверждается данными компьютерной микропериметрии и СОKT.

\section{Литература}

1. Балашова Л. М., Зайцева Н. С., Саксонова Е. О. и др. Патогенетические факторы развития пролиферативной витреоретинопатии при дистрофической отслойке сетчатки. Пролиферативный синдром в офтальмологии. 2000; (1): 12-3.

2. Campochiaro PA. Pathogenic mechanisms in proliferative vitreoretinopathy. Archives of ophthalmology. 1997; 115 (2): 407-8.

3. Pastor JC. Proliferative vitreoretinopathy: an overview. Survey of Ophthalmology. 1998; 43 (1): 3-18.

4. Качалина Г. Ф., Дога А. В., Касмынина Т. А., Куранова О. И. Эпиретинальный фиброз: патогенез, исходы, способы лечения. Офтальмохирургия. 2013; (4): 108-10.

5. Захаров В. Д., Борзенок С. А., Горшком И. М., Колесник С. В., Колесник А. И., Миридонова А. В. Этиопатогенетические аспекты и роль структур витреоретинального интерфейса в формировании идиопатических эпиретинальных мембран. Практическая медицина. 2018; 114 (3): 71-6.

6. Пономерёва Е. Н., Казарян А. А. Структурно-функциональные особенности макулярной зоны сетчатки при идиопатической эпиретинальной мембране. Российский офттальмологический журнал. 2013; 6 (2): 66-9.

7. Guidry C. The role of Muller cells in fibrocontractive retinal disorders. Progress in Retinal and Eye Research. 2005; 24 (1): 75-86.

8. Harada C, Mitamura Y, Harada T. The role of cytokines and trophic factors in epiretinal membranes: Involvement of signal transduction in glial cells. Progress in Retinal and Eye Research. 2006; 25 (2): 149-64.

9. Zhao F, Gandorfer A, Haritoglou C. Epiretinal cell proliferation in macular pucker and vitreomacular traction syndrome: analysis of flat-mounted internal limiting membrane specimens. Retina. 2013; 33 (1): 77-88.

10. Joshi M, Agrawal S, Christoforidis JB. Inflammatory mechanisms of idiopathic epiretinal membrane formation. Mediators Inflammation. 2013; DOI: 10.1155/2013/192582.

11. Speca S, Giusti I, Rieder F, Latella G. Cellular and molecular

\section{References}

1. Balashova LM, Zaǐceva NS, Saksonova EO i dr. Patogeneticheskie faktory razvitiya proliferativnoǏ vitreoretinopatii pri distroficheskoI otsloike setchatki. Proliferativnyı̌ sindrom v oftal'mologii. 2000; (1) 12-3.

2. Campochiaro PA. Pathogenic mechanisms in proliferative vitreoretinopathy. Archives of ophthalmology. 1997; 115 (2): 407-8.

3. Pastor JC. Proliferative vitreoretinopathy: an overview. Survey of Ophthalmology. 1998; 43 (1): 3-18.

4. Kachalina GF, Doga AV, Kasmynina TA, Kuranova OI. Epiretinal'ny fibroz: patogenez, iskhody, sposoby lecheniya. Oftal'mohirurgiya. 2013; (4): 108-10.

\section{ВЫВОДЫ}

Предложенная технология комбинированного лазерного лечения показала высокую эфффективность по отношению к группе контроля и группе сравнения, отражаясь в сохранении/увеличении зрительно-функциональных показателей и стабилизации/улучшении морфофункциональных показателей сетчатки в течение всего периода наблюдения. Показана безопасность разработанной технологии в отношении морфо-фуункциональных структур сенсорной сетчатки, которая отражается в увеличении показатетей светочувствительности сетчатки на различных сроках наблюдения.

mechanisms of intestinal fibrosis. World Journal of Gastroenterology. 2012; 18 (28): 3635-61.

12. Шурыгина И. А. и др. Фибробласты и их роль в развитии соединительной ткани. Сибирский медицинский журнал (Иркутск). 2012; 110 (3): 8-12.

13. Hinz B, Gabbiani G. Fibrosis: recent advances in myofibroblast biology and new therapeutic perspectives. Molecular Biology Reports. 2010; (2): 78.

14. Gass JDM. Macular dysfunction caused by epiretinal membrane contraction. In: Stereoscopic Atlas of Macular Diseases: Diagnosis and Treatment. 1997; 2 (4): 938-50.

15. Куранова О. И. Изучение эффективности микроимпульсного лазерного воздействия длиной волны 577 нм при макулярном отеке после хирургического удаления идиопатической эпиретинальной мембраны (диссертация). 2014; 33.

16. Захаров В. Д., Борзенок С. А., Горшков И. М., Колесник С. В., Колесник А. И., Куприянова А. Г., Островский Д. С., Миридонова А. В. Клинико-экспериментальная оценка раннего хирургического лечения идиопатических эпиретинальных мембран у пациентов с начальными признаками патологического процесса. Современные технологиив офтальмологии. 2018; 21 (1): 127-30

17. Pichi F, Lembo A, Morara M, Veronese C, Alkabes M, Nucci P Ciardella A. Early and late inner retinal changes after inner limiting membrane peeling. International Ophthalmology. 2013; 34 (2): 437-46.

18. Mazit C, Scholtes F. Assessment of macular profile using optical coherens tomography after epiretinal membrane surgery. Journal Français D'Ophtalmologie. 2008; 31 (7): 667-72.

19. Bu S, Kuijer R, Li X, Hooymans J, Los L. Idiopathic epiretinal membrane. Retina. 2014; 34 (12): 2317-35

20. Тахчиди Х. П., Качалина Г. Ф., Касмынина Т. А., Тебина Е. П. Способ комбинированного лазерного лечения начальной стадии эпиретинального фиброза. Патент РФ № 2634684. 02.11 .2017
5. Zaharov VD, Borzenok SA, Gorshkom IM, Kolesnik SV, Kolesnik Al, Miridonova AV. Etiopatogeneticheskie aspekty i rol' struktur vitreoretinal'nogo interfejsa $v$ formirovanii idiopaticheskih epiretinal'nyh membran. Prakticheskaya medicina. 2018; 114 (3): 71-6.

6. Ponomeryova EN, Kazaryan AA. Strukturno-funkcional'nye osobennosti makulyarnoj zony setchatki pri idiopaticheskoj epiretinal'noj membrane. Rossijskij oftal'mologicheskij zhurnal. 2013; 6 (2): 66-9.

7. Guidry C. The role of Muller cells in fibrocontractive retinal disorders. Progress in Retinal and Eye Research. 2005; 24 (1): 75-86.

8. Harada C, Mitamura Y, Harada T. The role of cytokines and 
trophic factors in epiretinal membranes: Involvement of signal transduction in glial cells. Progress in Retinal and Eye Research. 2006; 25 (2): 149-64.

9. Zhao F, Gandorfer A, Haritoglou C. Epiretinal cell proliferation in macular pucker and vitreomacular traction syndrome: analysis of flat-mounted internal limiting membrane specimens. Retina. 2013; 33 (1): 77-88.

10. Joshi M, Agrawal S, Christoforidis JB. Inflammatory mechanisms of idiopathic epiretinal membrane formation. Mediators Inflammation. 2013; DOI: 10.1155/2013/192582.

11. Speca S, Giusti I, Rieder F, Latella G. Cellular and molecular mechanisms of intestinal fibrosis. World Journal of Gastroenterology. 2012; 18 (28): 3635-61.

12. Shurygina IA i dr. Fibroblasty I in rol' $v$ razvitii soedinitel'noj tkani. Sibirskiĭ medicinskiĭ zhurnal. 2012; 110 (3): 8-12.

13. Hinz B, Gabbiani G. Fibrosis: recent advances in myofibroblast biology and new therapeutic perspectives. Molecular Biology Reports. 2010; (2): 78

14. Gass JDM. Macular dysfunction caused by epiretinal membrane contraction. In: Stereoscopic Atlas of Macular Diseases: Diagnosis and Treatment. 1997; 2 (4): 938-50.

15. Kuranova OI. Izuchenie effektivnosti mikroimpul'snogo lazernogo vozdejstviya dlinoj volny $577 \mathrm{~nm}$ pri makulyarnom oteke posle hirurgicheskogo udaleniya idiopaticheskoj epiretinal'noj membrany (dissertation). 2014; 33

16. Zaharov VD, Borzenok SA, Gorshkov IM, Kolesnik SV, Kolesnik Al, Kupriyanova AG, Ostrovskij DS, Miridonova AV. Klinikoeksperimental'naya ocenka rannego hirurgicheskogo lecheniya idiopaticheskih epiretinal'nyh membran u pacientov s nachal'nymi priznakami patologicheskogo processa. Sovremennye tekhnologii v oftal'mologii. 2018; 21 (1): 127-30.

17. Pichi F, Lembo A, Morara M, Veronese C, Alkabes M, Nucci P. Ciardella A. Early and late inner retinal changes after inner limiting membrane peeling. International Ophthalmology. 2013; 34 (2): 437-46.

18. Mazit C, Scholtes F. Assessment of macular profile using optical coherens tomography after epiretinal membrane surgery. Journal Français D'Ophtalmologie. 2008; 31 (7): 667-72.

19. Bu S, Kuijer R, Li X, Hooymans J, Los L. Idiopathic epiretinal membrane. Retina. 2014; 34 (12): 2317-35.

20. Tahchidi HP, Kachalina GF, Kasmynina TA, Tebina EP. Sposob kombinirovannogo lazernogo lecheniya nachal'noj stadii epiretinal'nogo fibroza. Russian Federation Patent RF № 2634684. 02.11.2017. 